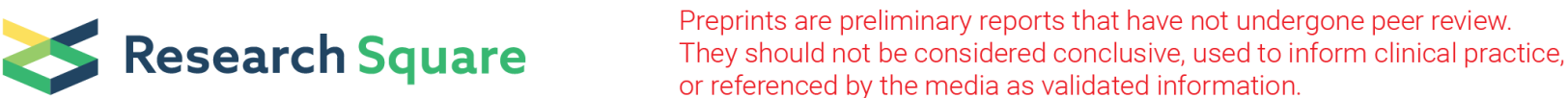

\section{Dental practice closure during COVID-19 and associated professional, practice and structural determinants: a multi-country survey}

Hams H Abdelrahman ( $\square$ hams.abdelrahman@alexu.edu.eg )

Alexandria University Faculty of Dentistry https://orcid.org/0000-0002-8727-6717

\section{Sara M Atteya}

Alexandria University Faculty of Dentistry

Merna Ihab

Alexandria University Faculty of Dentistry

Myat Nyan

University of Dental Medicine Mandalay

Diah Ayu Maharani

Universitas Indonesia Faculty of Dentistry

Anton Rahardjo

Universitas Indonesia Faculty of Dentistry

Mohammed Shaath

ParkHouse Dental Group

Khalid Aboalshamat

Umm Al-Qura University College of Dentistry

Sayda Butool

National institute of Medical Sciences University and Research

Anas Shamala

University of Science and Technology, Sanaa

Lubna Baig

Jinnah Sindh Medical University

Maha El Tantawi

Alexandria University Faculty of Dentistry

\section{Research}

Keywords: COVID-19, dentists, dental clinics, private practice, hospital bed capacity, fear

Posted Date: August 19th, 2020

DOl: https://doi.org/10.21203/rs.3.rs-59621/v1 
License: (c) (i) This work is licensed under a Creative Commons Attribution 4.0 International License. Read Full License 


\section{Abstract}

Background: The outbreak of novel coronavirus disease (COVID-19) in China has influenced every aspect of life worldwide. Due to the characteristics of dental settings, the risk of cross infection may be high between dental practitioners and patients. Being on the list of high-risk professions, dentists are very much expected to develop severe anxiety about the current pandemic situation. In addition, the limited provision of services and closure of dental practices raised concerns among dental professionals about the financial consequences of this closure. Therefore, the study assessed the extent of dental practice closure in various countries around the world, factors associated with this closure and whether closure and associated factors differed between private and non-private sectors.

Methods: From April to May 2020, a web-based survey was sent to dentists in several countries. The survey assessed professional factors, practice factors and country-level structural factors. Multilevel logistic regression was used to assess the association of practice closure with these factors. Effect modification due to private and non-private sectors was assessed.

Results: Dentists $(n=3243)$ participated from 29 countries. The majority $(75.9 \%)$ reported practice closure with significantly higher percentage in the private than non-private sector. Fears were associated with significantly higher likelihood of closure in private $(\mathrm{OR}=1.54,95 \% \mathrm{Cl}=1.24,1.92)$ and non-private sectors $(\mathrm{OR}=1.38,95 \% \mathrm{Cl}=1.04,1.82)$. Non-private, governmental sector dentists $(\mathrm{OR}=0.54,95 \% \mathrm{Cl}=0.31,0.94)$ and those in rural areas $(\mathrm{OR}=0.58,95 \% \mathrm{Cl}=0.42,0.81)$ and those in hospitals (overall $\mathrm{OR}=0.60,95 \% \mathrm{Cl}=$ $0.36,0.99)$ reported low likelihood of closure. High likelihood of closure was reported by those in academia $(\mathrm{OR}=2.13,95 \% \mathrm{Cl}=1.23,3.71)$. More hospital beds were associated with lower likelihood of closure in the non-private sector $(\mathrm{OR}=0.65,95 \% \mathrm{Cl}=0.46,0.91)$ and private sector dentists in high income countries (HICs) reported less closure than in non-HICs $(\mathrm{OR}=0.55,95 \%=0.15,1.93)$.

Conclusions: Most dentists reported practice closure because of COVID-19 with greater impact in the private than non-private sectors with professional, practice and country-level factors associated.

\section{Background}

On January $8^{\text {th }} 2020$, the Chinese Center for Disease Control and Prevention declared that the novel coronavirus caused COVID-19 [1]. Since that time, COVID-19 has become a major public health problem for all countries globally, changing all aspects of life [2]. As of 19 June, COVID-19 cases have been reported in 47 countries in Africa, 15 countries in the Western Pacific region, 53 countries in the European region, 10 countries in South East Asia, 21 countries in the Eastern Mediterranean region and 35 countries in the region of Americas with a total of 8.7 million laboratory-confirmed cases and about half a million deaths [3].

Transmission of COVID-19 occurs interpersonally via respiratory droplets and contact [4], inhalation, ingestion or direct mucous contact with saliva droplets [5]. The virus can survive on hands, objects or surfaces previously exposed to infected saliva [5]. COVID-19 incubation period ranges from 5 to 14 days 
$[1,6]$. The clinical manifestations may present as mild, flu-like symptoms, including fever $(98 \%)$ and dry cough (76\%). Patients may develop respiratory failure and multiple organ failure leading to death. Lymphocytopenia is observed, and chest CT examination usually shows ground-glass appearance of the lungs. No vaccine or specific antiviral therapy is available and supportive treatment, with organ support in intensive care units, remain the clinical management strategies [7].

Healthcare professionals are at the forefront of the fight against COVID-19 with cases of infection and varying numbers of fatality in different countries [8]. Due to the unique nature of dental practice, the risk of cross-infection is high among dental health personnel compared to other health care professionals [9, 10]. In addition, the virus was recently identified in the saliva of infected patients [11]. These factors increase dentists' fears and anxiety due to the COVID-19 pandemic compared to what is reported for the general public in the media [12].

After the pandemic, routine dental care was restricted to help flatten the curve and protect patients and personnel against infection. Urgent care was delivered using personal protective equipment (PPE) with additional precautions including taking patients' recent travel history, assessing signs and symptoms of infection, recording patients' body temperature, using $1 \%$ hydrogen peroxide as mouth rinse before dental procedures, using rubber dam and high volume suction and frequently cleaning and disinfecting public contact areas including door handles, chairs and washrooms [13]. The reduced availability of dental care might have increased the demand on the already burdened hospitals emergency departments [14], with potential impact on oral health and quality of life of patients. In addition, the limited provision of services and closure of dental practices raised concerns among dental professionals about the financial consequences of this closure [15]. Reports show that dental economy and other health care sectors were at a virtual standstill because of the pandemic $[15,16]$.

The disruption of the delivery of dental care may affect dental care providers, other health care sectors and the general public. Assessing the extent of this service disruption and its determinants is important to help mitigate its impact and plan supportive measures. The present study assessed the extent of dental practice closure among dentists from countries all over the world, the factors associated with this closure and whether closure and associated factors differed between the private and non-private sectors. The null hypothesis of the study was that dental practice closure was affected neither by professional dentist attributes (such as COVID-19 knowledge and fears), practice attributes (working in private or non-private sectors, urban or rural areas and solo or group practices) nor country attributes (number of hospital beds representing the country's ability to mobilize resources to control the disease and income level indicating the level of support to dentists in case of practice closure).

\section{Methods}

\section{Design}


A cross-sectional, multi-country, web-based survey was conducted from April to May 2020. The Ethics Review Committee approved the study, and it was carried out in agreement with the Declaration of Helsinki.

\section{Participants and sample size}

The target population was dentists of various specialties across the globe. The study recruited specialists and non-specialists practicing in various sectors during the study period. Dental students and interns were excluded. Sample size was estimated based on assuming that 50\% of dentists would report practice closure. Thus, based on a margin of error= $5 \%$ and $95 \%$ confidence level, sample size was calculated [17] to be 377 dentists. A greater number of participants was included because of the multi-country nature of the study and because it was not possible to limit the number of participants on social media once the link was posted.

\section{Questionnaire design and pilot testing}

The questionnaire (Additional file 1) was designed based on information in the websites of the World Health Organization (WHO), American Dental Association, and Center for Disease Control about dental settings and considerations for treatment during the COVID-19 outbreak in addition to previous studies [18]. A group of experts evaluated the original English questionnaire and confirmed its content validity and the logical structure of the questions. The questionnaire was further tested among 15 dentists, and few modifications for clarification were done. In addition, the survey was translated into German and Italian by two independent bilingual dentists. Using back translation, the translated questionnaires were compared with the original English version to identify discrepancies and resolve vagueness. The German version was pilot tested by 14 dentists and 11 dentists tested the Italian version. Pilot testing results were not included in the analysis.

At the beginning of the survey, a short introduction described the study purpose and assured participants of the confidentiality of their responses. There were 31 close-ended questions divided into three sections. Section 1 gathered information about the sociodemographic and practice characteristics of participants, including age, gender, country of practice, specialty, area of practice (rural or urban), and type of practice (private, governmental or academic sectors, solo, group or hospital practices). Section 2 consisted of 8 items assessing dentists' fears regarding COVID-19, with responses on a 5-point Likert scale ranging from strongly agree (code 5) to strongly disagree (code 1). Section 3 consisted of 15 questions assessing knowledge of measures to control the transmission of COVID-19 with possible responses being yes, no and do not know. A final question assessed whether dental practice was closed at the time of the survey.

\section{Data collection}


A link to the web-based questionnaire was created using the online survey platform "Survey Monkey". Respondents could revise and change their answers before submission and no duplicate entries were allowed. The questionnaire took 5-7 minutes to complete. The link was sent to collaborators in several countries. Convenience and snowball sampling were used to promote the link via Facebook and Instagram dentist-only groups, Linkedln, Twitter, and WhatsApp. All participants were asked to share the survey with their dental contacts.

\section{Statistical Analysis}

The overall fears and threats score were calculated by averaging the scores of the 8 items to give a score ranging from 1 to 5 . The overall knowledge score was created by assigning one point for each correct answer and adding the points of the 15 items with potential score ranging from zero to 15 . Cronbach's alpha was used to assess the internal consistency of the fears and knowledge items [19]. Multilevel logistic regression analysis was used to assess the association between the dependent variable (practice closure with yes/ no responses) and explanatory variables as fixed effects. These included level 1 professional and practice factors in addition to level 2 country-level structural factors including number of beds per 1000 population obtained from the World Bank Databank [20]. In the absence of multicountry data about the number of intensive care units needed to care for patients with COVID-19 complications, we used the number of beds per 1000 population. This is an indicator of the availability of inpatient services [21], and reflects demand and supply health care factors [20]. Country level structural factors also included income level based on the World Bank classification of countries into high income (HICs) with gross national income (GNI) > 12,375 US\$, upper middle income (UMICs) with GNI between 3,996 and 12,375 US\$, lower middle income (LMICs) with GNI between 1,026 and 3,995 US\$ and low income (LICs) with GNI<1,026 US\$ [22]. These categories were recoded into HICs and non-HICs. Country was included as random effect factor. Robust estimation was used to handle violations of model assumptions. A model was developed for the whole sample and two additional models were developed for participants working in the private sector and those working in the non-private sector. Odds ratios and 95\% confidence intervals (Cls) were calculated. Effect modification by private sector status was assessed and $p$ values were computed for this interaction. Significance level was set at 5\%. SPSS version 25.0 [23] was used for statistical analysis.

\section{Results}

About 3243 dentists responded from 29 countries (Additional file 2). Of these, 49.2\% were 20-30 years old, $56.8 \%$ were females and $70.6 \%$ were specialists. Also, $65.6 \%$ worked in the private sector, $52.3 \%$ were in group practice and $81.8 \%$ worked in urban locations. The mean (SD) number of beds/ 1000 population was $1.70(0.99)$ and $71.7 \%$ of dentists were from non-HICs. Most participants (75.9\%) reported that their practices were closed because of the pandemic (Table 1). Significantly higher percentage of dentists working in the private sector than non- private sector reported practice closure $(78.3 \%$ and $71.3 \%, \mathrm{P}<$ 0.0001). 
Table 2 shows the level of fear due to COVID-19. The greatest fear was about family members catching infection (mean $=4.36$ ) and the high infection risk among health care personnel (mean= 4.21). Cronbach alpha for the internal consistency of fear items was 0.70 . The mean fear score $=4.14$ out of $5, S D=0.54$. Figure 1 shows that $>95 \%$ of dentists had correct knowledge of COVID-19 symptoms, that it can be transmitted through respiratory secretions, that specific training is needed to prevent infection and that precautions are needed against droplet, contact and airborne infections. Cronbach alpha for the internal consistency of knowledge items was 0.62 . The mean knowledge score $=13.08$ out of $15, S D=1.89$.

Table 3 shows the factors associated with practice closure. Working in the private sector significantly modified the association between practice closure and specialization $(P=0.03)$ with significantly greater likelihood of closure reported by private sector general practitioners than specialists $(\mathrm{OR}=1.38,95 \% \mathrm{Cl}=$ $1.04,1.95)$. The association among non-private sectors dentists was weaker and not statistically significant $(\mathrm{OR}=1.08,95 \% \mathrm{Cl}=0.77,1.53)$. Fears were associated with significantly more closure among private sector $(\mathrm{OR}=1.54,95 \% \mathrm{Cl}=1.24,1.92)$ and non-private sector $(\mathrm{OR}=1.38,95 \% \mathrm{Cl}=1.04,1.82)$ dentists.

There were no significant differences between the private and non-private sectors in the association between closure and some practice factors such as working in academia $(P=0.13)$ and in hospitals $(P=$ 0.64). Working in academia was associated with significantly higher odds of closure overall than not working in academia $(\mathrm{OR}=2.13,95 \% \mathrm{Cl}=1.23,3.71)$ while working in hospitals was associated with significantly lower odds of closure overall than not working in hospitals $(\mathrm{OR}=0.60,95 \% \mathrm{Cl}=0.36,0.99)$.

There were significant differences between the private and non-private sectors in the association between practice closure and working in the governmental sector $(P=0.01)$ and urban/ rural location of practice $(P=0.001)$. Non-private sector dentists who worked in the governmental sector were significantly less likely than those in non-governmental sector to report practice closure $(\mathrm{OR}=0.54,95 \% \mathrm{Cl}=0.31,0.94)$. Private sector dentists working in the governmental sector reported higher but non-significant odds of closure $(\mathrm{OR}=1.19,95 \% \mathrm{Cl}=0.87,1.62)$. For the whole sample $(\mathrm{OR}=0.58,95 \% \mathrm{Cl}=42,0.81)$ and non-private sector dentists $(\mathrm{OR}=0.58,95 \% \mathrm{Cl}=0.42,0.81)$, the odds of practice closure were lower in rural than urban areas. For private sector dentists, the odds of practice closure were non-significantly higher in rural than urban locations $(\mathrm{OR}=1.29,95 \% \mathrm{Cl}=0.91,1.82)$.

There were no significant differences between private and non-private sectors in the association between practice closure and structural factors such as the number of hospital beds $(P=0.96)$ and country high income $(P=0.64)$. More hospital beds were associated with significantly lower odds of practice closure among dentists in non-private sector $(\mathrm{OR}=0.65,95 \% \mathrm{Cl}=0.46,0.91)$. Private sector dentists from HICs were non-significantly less likely to report practice closure than those from non-HICs $(\mathrm{OR}=0.55,95 \% \mathrm{Cl}=$ $0.15,1.93)$.

\section{Discussion}


The study showed that from April to May 2020, $75.9 \%$ of dentists reported closure with higher percentage in than outside the private sector. Dentists in the private sector, who were general practitioners, in solo practices, in rural areas and with greater COVID-19 fears were more likely to report practice closure. Country-level determinants also affected practice closure: better prepared health care systems were associated with less closure outside the private sector while the private sector in rich countries was less likely to close. The null hypothesis can, thus, be rejected. The study provides evidence of the impact of COVID-19 on dental practice closure which jeopardizes the provision of dental care. These findings have implications for planning support packages for the profession and the public.

In the present study, $75 \%$ of dentists reported practice closure. International guidelines related to provision of dental care during the pandemic ranged from allowing only public stomatological and general hospitals to deal with emergency cases in China [24], urging practitioners to shut their practices in California, USA [25]; decreasing the number of daily check-ups in the UK [26] to no guidance [27]. The level of dental practice closure in the present study was higher than that reported for non- dental specialties in a WHO survey of 155 countries where $53 \%$ reported disruption of treatment services for hypertension, $49 \%$ for diabetes and related complications, $42 \%$ for cancer and $31 \%$ for cardiovascular emergencies [28]. The level of practice closure in the present study was similar to that reported in the USA where $79 \%$ of dental of practices were closed except for emergency care [29]. The impact of this suspension of dental care on the oral health of the population is yet to be quantified.

In the present study, fear of reduced income because of the pandemic was among the three top fears. Similarly, reports showed lower patient volume following the public's avoidance of healthcare settings due to fear of COVID-19 which lead to financial losses in dental practices and reduced ability to pay employees. A US survey conducted in March 2020 reported that $28 \%$ of dentists were unable to pay their staff and $45 \%$ made partial payments [30,31]. It was estimated that if the current lockdown continues to September $2020,46 \%$ of dentists may need to file for bankruptcy [29]. This financial crisis is not likely to end in the coming period with potentially huge impact on the profession in the future. In the present study, fear of infection was one of the strongest factors associated with practice closure among self-employed dentists in the private sector which agrees with a study reporting that high level of anxiety was associated with more dentists indicating a desire to close their practices [32].

In the present study, dentists in academia were more likely to report practice closure. This agrees with previous data from North America indicating that dental care in teaching clinics was suspended and only emergency treatment was offered [30]. The study also showed that dentists working in hospitals were less likely to report practice closure. This may be attributed to the high level of preparedness of hospitals. For example, some hospitals designated for the care of COVID-19 patients were equipped with high level PPE for aerosol generating dental procedures $[33,34]$ with strict infection control measures and more dental units to meet patients' need for emergency dental services $[27,35,36]$.

The study showed less closure in group practices and more closure in solo practices. Large, group practices may be more resilient at times of financial hardship than small solo practices because they 
generally have more reserves and can pool resources to bridge the crisis. Small-scale health care providers tend to be less profitable which may increase their vulnerability to financial threats [37].

The study showed that compared to urban practices, there was more closure in private sector rural practices and less closure in non-private sector rural practices. Private sector rural healthcare facilities usually operate on thin profit margins, have small number of staff and less PPE against COVID-19 which put them at greater risk of closure to reduce financial and infection risks [38-40]. Consequently, nonprivate sector rural practices may be the only type of facility left to provide care for the local population and hence the reported less closure.

In the present study, practice closure was also associated with country-level determinants. More hospital beds were associated with less closure in the non-private sector. Countries with low-resources and underprepared healthcare systems may have less capacity to manage COVID-19 complications resulting in higher mortality rates, panic and anxiety that increase the chances of dental practice closure [41, 42]. In addition, the study showed less private practice closure in HICs. This agrees with reports that some HICs governments- such as Canada, Ireland and the UK-providing financial support for dental practices to avoid closure due to economic losses; offering funds, loans and credits to face issues of payment of salaries and supplies [31,43-46]. In addition, the generally higher income in HICs may provide financial sustainability in spite of decreased revenues and reduce the need for practice closure. No such measures were reported from LICs, LMICs or UMICs where no economic response plans were made to support the dental industry despite their needs.

The study is limited by its cross-sectional design which cannot provide proof of causality and by the convenience sampling which cannot support statistical representativeness. However, it included a large number of dentists from many countries all over the world with different professional and healthcare systems background which increases the generalizability of findings. The findings provide estimates of practice closure in many countries around the world that can be used to assess COVID-19 impact on the oral health of the public with potential implications for dental education. Assisting the dental industry, especially self-employed dentists in the private sector, may help retain skillful personnel and avoid devastating impact on dental services. Future studies are needed to assess the long-term impact of closure on the financial, psychologic and professional outcomes of dentists.

\section{Conclusions}

COVID-19 had a considerable impact on dental practice around the globe. Most dentists reported practice closure because of COVID-19 with greater impact in the private than non-private sector. Personal, professional and country-level factors were associated with practice closure. The findings help provide a profile of dentists with practices at greater risk of closure to plan for support packages.

\section{Abbreviations}


PPE: Personal Protective Equipment

WHO: World Health Organization

HICs: High Income Countries

GNI: Gross National Income

UMICs: Upper Middle Income Countries

LMICs: Lower Middle Income Countries

LICs: Lower Income Countries

Cls: Confidence Intervals

SPSS: Statistical Package for Social Sciences

SD: Standard Deviation

OR: Odds Ratio

\section{Declarations}

\section{Ethics approval and consent to participate}

The Ethics Review Committee, Faculty of Dentistry, Alexandria, Egypt approved the study (IRB No: 00010556-IORG 0008839), and the study was carried out in agreement with the Declaration of Helsinki. Ethical explanations of the study's purposes, anonymous data collection, confidentiality, and publication were mentioned in the first page of the online survey's webpage.

\section{Consent for publication}

Not applicable.

\section{Availability of data and materials}

The datasets used and/or analysed during the current study are available from the corresponding author on reasonable request.

\section{Competing interests}

The authors declare that they have no competing interests. 


\section{Funding}

This research did not receive any specific grant from funding agencies in the public, commercial, or notfor-profit sectors.

\section{Authors' contributions}

HA, SA, MI and MET conceptualized and designed the study, coordinated the data collection in Egypt, supported the analysis and interpretation of the data and drafted the manuscript. MN collected data in Mynamar and reviewed drafts of the manuscript. DAM and AR contributed to the design of the study, collected and analyzed the data in Indonesia and reviewed drafts of the manuscript. MS contributed to data collection and organization in UK and reviewed drafts of the manuscript. KS contributed to the analysis and interpretation of the KSA's data and reviewed drafts of the manuscript. SB, AS and LB contributed to the analysis and interpretation of the data from India, Yemen and Pakistan, respectively and reviewed drafts of the manuscript. All authors contributed to the interpretation and findings of the discussion, as well as the critical revision and final approval of the version to publish.

\section{Acknowledgements}

Not applicable.

\section{References}

1. Li Q, Guan X, Wu P, Wang X, Zhou L, Tong Y, et al. Early transmission dynamics in Wuhan, China, of novel coronavirus-infected pneumonia. New England Journal of Medicine. 2020;382:1199-207. doi:10.1056/NEJMoa2001316.

2. Phelan AL, Katz R, Gostin LO. The Novel Coronavirus Originating in Wuhan, China: Challenges for Global Health Governance. Journal of the American Medical Association. 2020;323:709-10. doi:10.1001/jama.2020.1097.

3. Mahase E. China coronavirus: WHO declares international emergency as death toll exceeds 200. BMJ. 2020;368:m408. doi:10.1136/bmj.m408.

4. Coronavirus Disease (COVID-19) Situation Reports. 2020. https://www.who.int/emergencies/diseases/novel-coronavirus-2019/situation-reports. Accessed 20 Jul 2020.

5. Peng X, Xu X, Li Y, Cheng L, Zhou X, Ren B. Transmission routes of 2019-nCoV and controls in dental practice. International Journal of Oral Science. 2020;12:1-6. doi:10.1038/s41368-020-0075-9.

6. Backer JA, Klinkenberg D, Wallinga J. Incubation period of 2019 novel coronavirus (2019-nCoV) infections among travellers from Wuhan, China, 2028 January 2020. Eurosurveillance. 2020;25:2000062. doi:10.2807/1560-7917.ES.2020.25.5.2000062. 
7. Pan Y, Guan H. Imaging changes in patients with 2019-nCov. European Radiology. 2020;30:3612-3. doi:10.1007/s00330-020-06713-z.

8. Ng K, Poon BH, Kiat Puar TH, Shan Quah JL, Loh WJ, Wong YJ, et al. COVID-19 and the Risk to Health Care Workers: A Case Report. Ann Intern Med. 2020;172:766-7. doi:10.7326/L20-0175.

9. The Workers Who Face the Greatest Coronavirus Risk - The New York Times. 2020. https://www.nytimes.com/interactive/2020/03/15/ business/economy/coronavirus-workerrisk.html. Accessed 20 July 2020.

10. Malik YS, Sircar S, Bhat S, Sharun K, Dhama K, Dadar M, et al. Emerging novel coronavirus (2019$\mathrm{nCoV}$ ) -current scenario, evolutionary perspective based on genome analysis and recent developments. Vet Q. 2020;40:68-76. doi:10.1080/01652176.2020.1727993.

11. To KK-W, Tsang OT-Y, Yip CC-Y, Chan K-H, Wu T-C, Chan JM-C, et al. Consistent Detection of 2019 Novel Coronavirus in Saliva. Clin Infect Dis. 2020.

12. Fazel M, Hoagwood K, Stephan S, Ford T. Mental health interventions in schools in high-income countries. The Lancet Psychiatry. 2014;1:377-87.

13. Ather A, Patel B, Ruparel NB, Diogenes A, Hargreaves KM. Coronavirus Disease 19 (COVID-19): Implications for Clinical Dental Care. Journal of Endodontics. 2020;46:584-95. doi:10.1016/j.joen.2020.03.008.

14. Wu M, Chang YC. COVID-19 and its implications in the management of resource infrastructure. Journal of Dental Sciences. 2020;15:225. doi:10.1016/j.jds.2020.04.008.

15. Coulthard P. Dentistry and coronavirus (COVID-19) - moral decision-making. Br Dent J. 2020;228:503-5. doi:10.1038/s41415-020-1482-1.

16. COVID Survey - The Larry A. Green Center. https://www.green-center.org/covid-survey. Accessed 20 Jul 2020.

17. Sample Size Calculator by Raosoft, Inc. http://www.raosoft.com/samplesize.html. Accessed 20 Jul 2020.

18. Abdollahi M, Ghahramanian A, Shahbazi S, Rezaei F, Naghili B, Asghari-Jafarabadi M. Developing a questionnaire to assess Iranian nurses' knowledge of and attitude to Middle East respiratory syndrome. East Mediterr Health J. 2020;26:506-16.

19. Ursachi G, Horodnic IA, Zait A. How Reliable are Measurement Scales? External Factors with Indirect Influence on Reliability Estimators. Procedia Econ Financ. 2015;20:679-86. doi:10.1016/s22125671(15)00123-9.

20. The World Bank. Hospital beds (per 1,000 people) | Data. The World Bank. 2018. https://data.worldbank.org/indicator/SH.MED.BEDS.ZS. Accessed 20 Jul 2020.

21. Mark Landry. Hospital beds (per 1,000 people). World Health Organisation. 2019. https://www.who.int/data/gho/indicator-metadata-registry/imr-details/3119. Accessed $20 \mathrm{Jul} 2020$.

22. Prydz EB, Wadhwa D. Classifying countries by income. The World Bank. 2019. https://datatopics.worldbank.org/world-development-indicators/stories/the-classification-of- 
countries-by-income.html. Accessed $20 \mathrm{Jul} 2020$.

23. IBM. 2015. IBM Corp. Released 2017. IBM SPSS Statistics for Windows, Version 25.0. Armonk, NY: IBM Corp.

24. Guo J, Xie H, Liang M, Wu H. COVID-19: a novel coronavirus and a novel challenge for oral healthcare. Clin Oral Investig. 2020;24:2137-8. doi:10.1007/s00784-020-03291-8.

25. CDA Presents. https://www.cda.org/Home/News-and-Events/CDA-Presents. Accessed 20 Jul 2020.

26. The Scottish Government - gov.scot. https://www.gov.scot/. Accessed 20 Jul 2020.

27. Alharbi A, Alharbi S, Alqaidi S. Guidelines for dental care provision during the COVID-19 pandemic. Saudi Dent J. 2020;32:181-6. doi:10.1016/j.sdentj.2020.04.001.

28. WHO. COVID-19 significantly impacts health services for noncommunicable diseases. World Health Organisation. 2020. https://www.who.int/news-room/detail/01-06-2020-covid-19-significantlyimpacts-health-services-for-noncommunicable-diseases. Accessed 20 Jul 2020.

29. Nasseh K, Vujicic M. Modeling the Impact of COVID-19 on U.S. Dental Spending. 2020. https://www.ada.org/ /media/ADA/Science and Research/HPI/Files/HPIBrief_0420_1.pdf?la=en. Accessed 20 Jul 2020.

30. Wu KY, Wu DT, Nguyen TT, Tran SD. COVID-19's impact on private practice and academic dentistry in North America. Oral Dis. 2020; doi:10.1111/odi.13444.

31. Farooq I, Ali S. COVID-19 outbreak and its monetary implications for dental practices, hospitals and healthcare workers. Postgraduate Medical Journal. 2020; doi:10.1136/postgradmedj-2020-137781.

32. Ahmed MA, Jouhar R, Ahmed N, Adnan S, Aftab M, Zafar MS, et al. Fear and practice modifications among dentists to combat novel coronavirus disease (COVID-19) outbreak. Int J Environ Res Public Health. 2020; doi:10.3390/ijerph17082821.

33. Jirka GP, Thompson W. Personal protective equipment. In: The A3 Workbook: Unlock Your ProblemSolving Mind. 2009; doi:10.1201/9781420071825-29.

34. Chamorro-Petronacci C, Martin Carreras-Presas C, Sanz-Marchena A, A Rodríguez-Fernández M, María Suárez-Quintanilla J, Rivas-Mundiña B, et al. Assessment of the Economic and Health-Care Impact of COVID-19 (SARS-CoV-2) on Public and Private Dental Surgeries in Spain: A Pilot Study. Int J Environ Res Public Health. 2020;17:5139. doi:10.3390/ijerph17145139.

35. Dave M, Seoudi N, Coulthard P. Urgent dental care for patients during the COVID-19 pandemic. The Lancet. 2020;395:1257. doi:10.1016/S0140-6736(20)30806-0.

36. Guo H, Zhou Y, Liu X, Tan J. The impact of the COVID-19 epidemic on the utilization of emergency dental services. J Dent Sci. 2020.

37. Kruse FM. For-Profit Hospitals Out of Business? Financial Sustainability During the COVID-19 Epidemic Emergency Response. Int J Heal Policy Manag. 2020; doi:10.34172/ijhpm.2020.67.

38. Kumar A, Rajasekharan Nayar K, Koya SF. COVID-19: Challenges and its consequences for rural health care in India. Public Heal Pract. 2020;1:100009. 
39. RURAL_HEALTH_CARE_AND_HEALTH_INSURANCE. 2020.

https://journalistsresource.org/studies/government/health-care/rural-health-care-covid-19-research/. Accessed 20 Jul 2020.

40. Rural Health and COVID-19. 2020. https://files.asprtracie.hhs.gov/documents/aspr-tracie-ruralhealth-and-covid-19.pdf. Accessed 20 Jul 2020.

41. Elhadi M, Msherghi A, Alkeelani M, Alsuyihili A, Khaled A, Buzreg A, et al. Concerns for low-resource countries, with under-prepared intensive care units, facing the COVID-19 pandemic. Infect Dis Heal. 2020; doi:10.1016/j.idh.2020.05.008.

42. Kasozi KI, Mujinya R, Bogere P, Ekou J, Zirintunda G, Ahimbisibwe S, et al. Pandemic panic and anxiety in developing countries. Embracing One Health offers practical strategies in management of COVID-19 for Africa. Pan Afr Med J. 2020;35 Suppl 2:3. doi:10.11604/pamj.2020.35.3.22637.

43. Canada government of. Canada's COVID-19 Economic Response Plan. Canada.Ca. 2020. https://www.canada.ca/en/department-finance/economic-response-plan.html. Accessed $20 \mathrm{Jul}$ 2020.

44. Evans S. Coronavirus - what's the financial impact on dentistry? 2020. https://www.dentistry.co.uk/2020/03/19/coronavirus-financial-impact-dentistry/. Accessed $20 \mathrm{Jul}$ 2020.

45. COVID-19 Updates \& Support | IDA Ireland. https://www.idaireland.com/how-we-help/covid19support-and-updates. Accessed 20 Jul 2020.

46. COVID-19 Business Loan. https://microfinanceireland.ie/loan-packages-2/covid19/. Accessed $20 \mathrm{Jul}$ 2020.

\section{Tables}

Table 1: Distribution of personal, professional and practice and structural factors among the study participants $(n=3243)$ 


\begin{tabular}{|c|c|c|}
\hline \multicolumn{2}{|l|}{ Factors } & $\mathrm{N}(\%)$ \\
\hline \multicolumn{3}{|l|}{ Personal } \\
\hline \multirow[t]{5}{*}{ Age } & $20-30$ & $1597(49.2)$ \\
\hline & $31-40$ & $986(30.4)$ \\
\hline & $41-50$ & $420(13)$ \\
\hline & $51-60$ & $193(6.0)$ \\
\hline & $61+$ & $47(1.4)$ \\
\hline \multirow[t]{2}{*}{ Gender } & Males & $1401(43.2)$ \\
\hline & Females & $1842(56.8)$ \\
\hline \multicolumn{3}{|l|}{ Professional and Practice } \\
\hline \multirow[t]{2}{*}{ Specialty } & Specialists & $2290(70.6)$ \\
\hline & General practitioners & $953(29.4)$ \\
\hline \multirow[t]{8}{*}{ Practice characteristic } & Private sector & $2123(65.6)$ \\
\hline & Governmental sector & $1263(38.9)$ \\
\hline & Academic sector & $528(16.3)$ \\
\hline & Solo practice & $1129(34.8)$ \\
\hline & Group practice & $1697(52.3)$ \\
\hline & Hospital & $998(30.8)$ \\
\hline & Urban location & $2653(81.8)$ \\
\hline & Rural location & $590(18.2)$ \\
\hline \multicolumn{3}{|l|}{ Structural } \\
\hline Number of beds/ 1000 population & Mean (SD) & $1.70(0.99)$ \\
\hline \multirow[t]{2}{*}{ High income countries } & Yes & $917(28.3 \%)$ \\
\hline & No & $2326(71.7 \%)$ \\
\hline \multirow[t]{2}{*}{ Practice closed because of the pandemic } & Yes & $2461(75.9)$ \\
\hline & No & $782(24.1)$ \\
\hline
\end{tabular}


Table 2: Levels of fears and perceived threat because of the COVID-19 pandemic reported by participating dentists

\begin{tabular}{|c|c|}
\hline Item & $\begin{array}{l}\text { Mean } \\
(\text { SD) }\end{array}$ \\
\hline $\begin{array}{l}\text { I am afraid of working in places where patients suspected of COVID-19 infection are } \\
\text { treated. }\end{array}$ & $\begin{array}{l}4.08 \\
(0.99)\end{array}$ \\
\hline I am afraid of providing dental care for patients infected with/ suspected of COVID-19. & $\begin{array}{l}4.14 \\
(1.00)\end{array}$ \\
\hline $\begin{array}{l}\text { In spite of PPE and infection prevention precautions, the risk of COVID-19 infection is high } \\
\text { among health care personnel. }\end{array}$ & $\begin{array}{l}4.21 \\
(0.89)\end{array}$ \\
\hline $\begin{array}{l}\text { Equipment and facilities required to protect HCP from COVID-19 infection are not } \\
\text { adequately provided in healthcare facilities }\end{array}$ & $\begin{array}{l}4.13 \\
(0.92)\end{array}$ \\
\hline $\begin{array}{l}\text { Healthcare personnel should be paid more when treating patients infected with/ suspected } \\
\text { of COVID-19 infection }\end{array}$ & $\begin{array}{l}3.91 \\
(1.13)\end{array}$ \\
\hline I am afraid that a family member may be affected by COVID-19 infection & $\begin{array}{l}4.36 \\
(0.90)\end{array}$ \\
\hline I am worried that my patients will not be receiving adequate care because of the outbreak. & $\begin{array}{l}4.08 \\
(0.79)\end{array}$ \\
\hline I am worried that my practice income would be affected because of the outbreak & $\begin{array}{l}4.16 \\
(0.92)\end{array}$ \\
\hline
\end{tabular}

Table 3: Factors associated with practice closure because of COVID-19 in multilevel regression in private and non-private sectors 


\begin{tabular}{|c|c|c|c|c|}
\hline \multirow[t]{2}{*}{ Factors } & $\begin{array}{l}\text { Private sector } \\
\mathrm{N}=2123\end{array}$ & $\begin{array}{l}\text { Non-private } \\
\text { sector } \\
\mathrm{N}=1120\end{array}$ & $\begin{array}{l}\text { All participants } \\
\mathrm{N}=3243\end{array}$ & \multirow[t]{2}{*}{$\begin{array}{l}\text { P of } \\
\text { interaction }\end{array}$} \\
\hline & OR $(95 \% \mathrm{Cl})$ & & & \\
\hline \multicolumn{5}{|l|}{ Professional factors } \\
\hline GP vs specialist & $\begin{array}{l}1.38(1.04 \\
1.85)^{*}\end{array}$ & $1.08(0.77,1.53)$ & $1.14(0.82,1.59)$ & $0.03^{\star}$ \\
\hline Fear score & $\begin{array}{l}1.54(1.24 \\
1.92)^{*}\end{array}$ & $1.38(1.04,1.82) *$ & $1.28(0.97,1.67)$ & 0.21 \\
\hline Knowledge score & $1.05(0.98,1.12)$ & $1.03(0.96,1.11)$ & $1.01(0.94,1.09)$ & 0.21 \\
\hline \multicolumn{5}{|l|}{ Practice factors } \\
\hline Governmental sector & $1.19(0.87,1.62)$ & $0.54(0.31,0.94) *$ & $\begin{array}{l}0.50(0.29 \\
0.86)^{*}\end{array}$ & $0.01 *$ \\
\hline Academic sector & $1.37(0.93,2.03)$ & $1.81(1.04,3.15) *$ & $\begin{array}{l}2.13(1.23 \\
3.71)^{*}\end{array}$ & 0.13 \\
\hline Solo practice & $1.45(1.00,2.10)$ & $1.14(0.66,1.97)$ & $1.13(0.65,1.94)$ & 0.50 \\
\hline Group practice & $0.88(0.60,1.29)$ & $0.79(0.49,1.28)$ & $0.80(0.49,1.29)$ & 0.85 \\
\hline Hospital & $\begin{array}{l}0.55(0.41 \\
0.75)^{\star}\end{array}$ & $0.58(0.35,0.97) \star$ & $\begin{array}{l}0.60(0.36 \\
0.99)^{*}\end{array}$ & 0.64 \\
\hline Rural vs urban & $1.29(0.91,1.82)$ & $0.58(0.42,0.81) \star$ & $\begin{array}{l}0.58(0.42 \\
0.81)^{*}\end{array}$ & $0.001 *$ \\
\hline \multicolumn{5}{|l|}{ Structural factors } \\
\hline $\begin{array}{l}\text { Beds/ } 1000 \\
\text { population }\end{array}$ & $1.01(0.72,1.41)$ & $0.65(0.46,0.91) *$ & $0.94(0.65,1.37)$ & 0.96 \\
\hline HICs vs non- HIC & $0.55(0.15,1.93)$ & $2.00(0.60,6.69)$ & $0.60(0.19,1.90)$ & 0.64 \\
\hline
\end{tabular}

The models are adjusted for gender and age. OR: odds ratio, Cl: confidence interval, GP: general practitioner, HIC: high income country

\section{Figures}


Preoperative $1 \%$ hydrogen peroxide mouth rinse should be used Environmental surfaces should be cleaned by $10 \%$ bleach COVID-19 is diagnosed by PCR of airways secretions Extraoral dental radiographies should be used Rubber dam and high rapid suction are mandatory Elective dental treatment should be postponed The incubation period of COVID-19 virus is 2-14 days COVID-19 virus can survive on environmental surfaces Hand hygiene prevents transmission

Urgent dental care should be minimally invasively Social distancing and removing reading sources $\&$ toys is needed Droplet, contact and airborne precautions are needed Specific training to prevent transmissionis needed Can be transmitted through respiratory tract secretions Symptoms of COVID-19

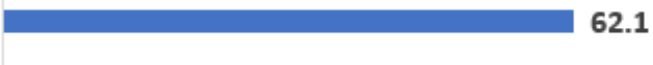

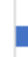

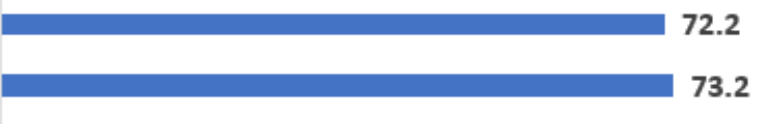

\section{西}

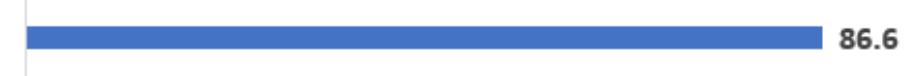

.

$$
\text { s }
$$
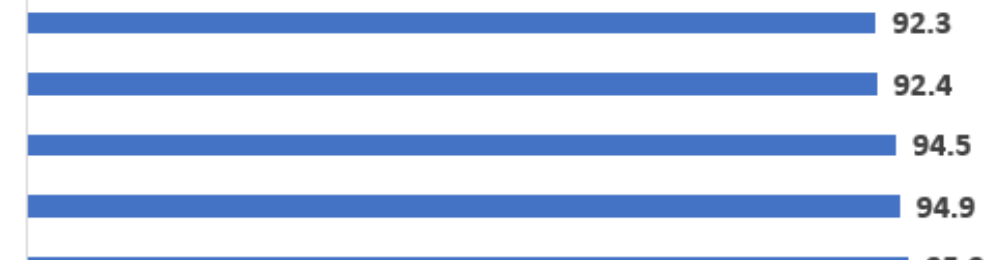

$\%$ correct responses

\section{Figure 1}

Correct responses regarding knowledge about COVID-19 pandemic

\section{Supplementary Files}

This is a list of supplementary files associated with this preprint. Click to download.

- Appendix.docx 